\title{
EDITORIAL
}

\section{MEDICINA INTERNA}

\author{
R. A. CALA
}

La Asociación Colombiana de Medicina Interna ha entrado en su etapa de madurez. Desde su comienzo hasta ahora, ha sido baluarte de una disciplina intelectual especial, que representa la Medicina Interna.

En su primera etapa se caracteriza como una sociedad aislada, agrupando internistas calificados, consolidando en Colombia la especialidad. Fueron los años sesenta, que recordamos sin duda por el academismo que brilló en nuestras Facultades de Medicina, época durante la cual la Medicina Interna adquiere personalidad en el país. La Asociación prosperó paralelamente y fué precisamente en este decenio cuando se programaron los cursos de post-grado, en colaboración con el American College of Physicians, que exitosamente se continúan desarrollando desde entonces. La Asociación se convirtió en un vínculo común para los internistas colombianos.

Una segunda etapa importante se inicia en 1969. William Rojas, Presidente de la Asociación, propone agrupar en un solo Congreso Nacional varias de las especialidades médicas, representadas hasta entonces en sociedades aisladas. La idea constituyó un éxito y también desde entonces, viene celebrándose cada dos años el Congreso

Dr. Roso Alfredo Cala Hederich: Presidente de la Asociación Colombiana de Medicina Interna.
Colombiano de Medicina Interna y Especialidades Médicas, que ha dado mayor solidez a este evento, cuya IV reunión se realiza este año, con la participación de trece sociedades.

Más recientemente, en 1974, la Asociación da otro paso importante. Bajo la Presidencia de Hernando Sarasti, se modifica la estructura y su característica centralista, reducida a una Junta Directiva Nacional, se transforma en un organismo integrado por capítulos regionales que representan las distintas secciones del país, dándosele más vida a la Asociación y permitiendo una participación más activa de todos sus miembros.

La Asociación ha crecido, se ha madurado y en la actualidad es una institución consolidada. Todos los Internistas Colombianos y particularmente quienes en una u otra forma hemos tenido el privilegio de dirigirla, podemos sentirnos orgullosos de pertenecer a ella, con la sensación sincera de que representa fielmente los intereses de nuestra especialidad.

Que es la Medicina Interna? Qué es ser Internista? Son preguntas que con frecuencia nos hacemos. Posiblemente no se han respondido adecuadamente, pero más que una respuesta $o$ una definición, lo importante es el reconocimiento del principio y significado filosófico de su concepto. 
Pertenecemos a una especialidad que nos imprime una personalidad médica especial, quizás por la razón de la misma universalidad científica que supone. La Medicina Interna es el núcleo de formación de cualquier especialidad médica. Así lo pensaba el profesor Carlos Trujillo Gutiérrez, cuando en los viejos salones del Hospital San Juan de Dios de Bogotá, decía: "Sobre el manto de la clínica tejamos el cuadro de la especialidad". Antes que cardiólogos, neurólogos o nefrólogos, debemos ser internistas. Cualquier idea de subespecialidad debe estar basada en una amplia concepción de la Medicina Interna, de la clínica general. Es la única manera como evitamos la fragmentación del contenido integral de la Medicina Interna.

El Internista debe ser el eje alrededor del cual se movilice todo el equipo de salud frente a un paciente. Es el asesor y consultante para otros especialistas; es el hombre que dirige y centraliza la acción médica, evitando la atomización del cuidado del enfermo.

Por estas mismas razones la formación del Internista no puede improvisarse. Más importante que exponer nuestros residentes al aprendizaje de una disciplina de procedimientos y conductas, es imprimirles la personalidad de ser Internistas, lo que quiere decir: Pensar, dirigir, actuar.

Cuál es el papel de la Asociación Colombiana de Medicina Interna según estos conceptos? Los objetivos están contemplados en sus estatutos. Vale la pena preguntarnos si esta acción debe extenderse más. Sería la Asociación el organismo calificado para determinar la certificación de los Internistas en Colombia? Se justificaría que la Asociación vigilara la organización de los Departamentos de Medicina Interna de nuestros hospitales y evaluara los programas docentes del pre y post-grado a través de Comités académicos debidamente calificados? La Asociación indudablemente puede evolucionar más en el desarrollo de sus programas y en el alcance de sus objetivos. Quizás en esta etapa de crisis académicas que vivimos, sea la Asociación el organismo revitalizador que genere nuevamente el entusiasmo perdido y termine esa pereza intelectual que nos ha invadido. También dentro de los programas gubernamentales la acción de la Asociación Co- lombiana de Medicina Interna es valedera.

La Asociación debe ser organismo de consulta para las instituciones oficiales. Si la medicina es punto esencial de los programas de cambio social que se proponen, es justamente cuando no sólo la Asociación, sino también todas las sociedades científicas, deben tener participación activa en la elaboración, estudio y desarrollo de estos programas que se refieren al bienestar y salud del país.

Todas estas consideraciones indican que debemos robustecer más la Asociación. Cualquier esfuerzo que se haga para mantenerla es justificado, Quizás más tarde la idea de William Rojas en 1969, pueda extenderse no ya a un Congreso, sino a la formación de una sola sociedad poderosa que constituya lo que podría ser el Colegio Colombiano de Medicina Interna y Especialidades Médicas.

Al dejar la Presidencia de la Asociación Colombiana de Medicina Interna, puedo con orgullo expresar una gran satisfacción: Hemos continuado la trayectoria de Juntas Directivas pasadas que llevaron la Asociación a un puesto de prestigio nacional y lo hemos mantenido. Entregamos una Asociación firme, creciente y digna de los miembros que representa. Quienes han de dirigirla en el futuro, tienen un desafío en sus manos. Para sus realizaciones cuentan con un grupo de Internistas Colombianos con quienes es estimulante trabajar,

Coincidiendo con la realización del IV Congreso Colombiano de Medicina Interna, aparece la revista "Acta Médica Colombiana". Es principal promotor de esta idea el Dr. Fernando Chalem, quien presentó su iniciativa a la Junta Directiva de la Asociación, en donde fué unánimemente respaldada, acordándose que la publicación sería el órgano oficial de la Asociación Colombiana de Medicina Interna.

"Acta Médica Colombiana" será una revista médica, para todos los Internistas del país y para los médicos generales y de otras especialidades, interesados en esta disciplina.

Puede Fernando Chalem sentirse orgulloso de esta realización cuyo éxito anticipamos. 